\title{
The Exploration of Cultivating the Research and Innovation Capacities of Agricultural Engineering Graduates
}

\author{
Li-qiu Shi, Jun-fa Wang*, Xiao-hai Li and Teng-fei Zhuang \\ School of Mechanical Engineering, Jiamusi University, Jiamusi, Heilongjiang, China
}

\begin{abstract}
It is great significance to improve the international competitiveness of China's agriculture for enhancing the China's agricultural mechanization professionals' research and innovation capacity. For that reason, teaching contents, teaching methods, assessment methods were intervened on the whole process to improve the graduate students of the major scientific research innovation ability in this paper. The entire process was regulated by a series of specific measures that adding innovation methods course; expand the teaching content, laying the foundation for innovation; researching on teaching methods, cultivate students' innovative quality; to strengthen the practice capability of students, build innovation environment; cultivating students' innovative quality; enhancing students' practical ability, creating an innovative environment; formulating proficiency test plan and evaluation standards. The practice results show that the graduates' inertia of thinking was broken; the students' horizons was developed; the graduates' enthusiasm of participation in a variety of innovative practices were increased; the graduates' efficiency of innovation and ability of innovation were enhancing in the development of new training model.
\end{abstract}

Keywords — agriculture mechanization, innovative capability, teaching methods

\section{培养农业工程学科研究生科研创新能力的探索 \\ 史立秋 王俊发* 李小海 庄腾飞 \\ 佳木斯大学机械工程学院, 佳木斯, 黑龙汇, 中国}

摘 要 提升我国农业机械化专业人才的科研创新能力对提高我国农业的国际竞争力具有重要意义。为此本文采用对教学内容、教 学方法、考核方式进行全过程干预来提高该专业研究生的科研创新能力进行了研究。通过增设创新方法课程; 拓展教学内容, 奠定创 新基础; 对教学方法进行研究, 培养学生的创新素质; 加强学生的实践能力, 营造创新环境; 制定能力考试实施方案及评定标准等一 系列具体措施, 进行全过程的调控。实践结果表明: 在新的培养模式制定下打破了研究生的思维惯性, 开拓了学生的视野, 增加了研 究生参与各种创新实践活动的积极性, 提升了研究生的创新效率和创新能力。

关键词 农业机械化，创新能力，教学方法

1. 引言

在当今社会科技创新是核心竞争力, 是一个国家迅速 发展的战略核心，是全面提高综合国力的关键举措。农业
机械化和现代化稳步推进离不开农业机械工程的发展和技 术革新, 近年来, 我国对农业科技技术的投入逐年增加, 农业机械化和现代化稳步推进，农业技术现代化的发展势

黑龙江省学位与研究生教育教学改革研究项目支持 (项目编号: JGXM_HLJ_2011123); 佳木斯大学教学研究专项项目支持 (项目编号: JYL2013-16)

作者：史立秋（1978一)，女，黑龙江佳木斯人，佳木斯大学机械工程学院副教授。

*通讯作者：王俊发 (1958-)，男，黑龙江佳木斯人，佳木斯大学机械工程学院教授; 
头良好。但是我国农业生产的科研水平和科技含量与国外 相比还相对落后, 因此, 我国应该加快农业机械化工程人 才队伍建设, 以加速农业机械化专业人才的科研创新能力 培养, 进而提高我国农业机械科研产品的国际竞争力[1-2]。 研究生是创新的重要群体, 然而当前农业机械化工程专业 研究生培养模式还存在诸多问题, 通过对硕士研究生的论 文抽查, 发现很少有令人兴奋的原创东西, 大都属于跟踪 性研究, 研究生的创新能力明显不足。对我国当前硕士研 究生培养上存在的差距与问题进行剖析可知: 目前国内在 研究生课程上还存在一些课程陈旧, 缺乏科技前沿内容讲 授、教学方式模式化、新学科建设不健全、专业学科结构 不合理等等现象, 不能更好地满足 21 世纪社会对研究生科 研人才的多样化、实用化等综合要求[3]。因此急需改革现 有研究生培养的模式, 虚心学习国外的成功经验, 不断丰 富完善我国研究生培养制度和建立科学、先进的培养体系 [4-5]。

如何通过农业工程学科研究生的教学试验改革与创新 能力培养, 培养出一名合格的创新性人才, 是刻不容缓的 问题。为此本文采用对教学内容、教学方法、考核方式进 行全过程干预来提高该专业研究生的科研创新能力进行了 研究。

\section{2. 研究过程}

本文通过(1)查阅文献法。到图书馆、资料室、书店和 网上搜寻[1]查阅相关档案文献资料, 收集并整理有关数据 资料; (2)比较分析法。本研究对传统和当下研究生教育、 创新能力的培养等情况进行比较、分析; (3)高校调查法。 本研究通过深入高水平大学研究生创新基地进行详尽的调 查, 了解其在研究生创新能力模式探索中所取得的成绩, 总结创新基地在运行中遇到的困难和具体的解决措施; (4) 试验实践法。将新的教学改革理论和培养研究生创新的新 方法应用到实际的教学改革实践中。

整个研究生培养模式是一个全过程干预的模式。进行 一次入学能力考试, 进行培养方式分类; 优化课程内容, 加强交叉学科、新兴学科知识的渗透与融合; 改革教学方 法, 培养创新素质; 加强实践能力, 营造创新环境。

\section{3. 科研创新能力提升的措施}

(1)制定录取后能力考试实施方案及评定标准。传统的 课程考核方式导致学生学习死记硬背、思维固化, 不利于 学生创新能力的培养。因此, 借鉴目前国外研究生培养模 式的成功经验, 建设“开放性课堂”, 建立与之适应的研究 生课程考核方式是改革课程教学与培养研究生创新能力的 关键环节。制定“农业工程学科全日制学术型研究生创新能
力基本要求及考核工作规定”制度, 将研究生的创新能力纳 入到课程考核方式内, 作为课程结业的成绩评定依据之一, 进一步提高学生的创新与实践能力, 并进行实际验证, 逐 步优化该方案及标准。

(2)优化课程内容, 加强交叉学科、新兴学科知识的渗 透与融合。农业机械化工程专业和其他机械工程专业相比 较, 具有显著的学科交叉特征[6-7]。农业机械应用在不同 的农业对象上, 其机械设计和工艺的要求也各不相同。不 了解各种农业对象的特性, 不熟悉各种农艺、园艺要求, 就无法设计出合格的农业机械。农业机械化工程的课程内 容不仅需要囊括机械设计制造、自动控制等传统机械领域 的所有知识, 还应当涉及农艺、园艺、食品、水产养殖、 生物技术等领域的相关知识。因此, 农业机械化工程专业 课程的设置不能局限于本专业学科领域, 还应注意跨学科 知识的学习。科学领域新的发现, 技术领域新的突破正推 动着工程学科的飞速发展。采用新的理论、新的方法, 应 用新的工艺、新材料, 已经成为工程领域创新性研究的发 展趋势。工程领域与其他领域知识的交叉与融合, 各学科 间研究方法的相互借鉴为工程领域创新性研究注入了新的 活力。在研究生选课时, 应给予学生更大的自由度, 鼓励 学生跨专业选课, 适当增大选修课在课程设置中的比重, 扩充知识面, 拓宽创新视野, 启迪创新能力。

(3)改革教学方法, 培养创新素质。采用“启发式”和“讨 论式”教学方法, 在传统教学观念的影响下, 我国研究生课 程教学还未脱离“填鸭式”的教学方法 [8-9]。在这种教学方 式下, 学生不经思考被动地学习知识, 缺少与任课教师之 间的互动交流, 学习气氛不活跃, 不利于学生创新能力的 培养。因此, 研究生课程教学方法上应进行适当的改革, 采用灵活多样的教学方法, 注重学生个性的培养。在教学 方法上可以借鉴国外研究生课堂教学的成功经验, 采用“启 发式”、“汇报式”和“讨论式”教学方法。例如目前国内研究 生教学课堂上就经常出现课堂“研讨会”。教师在介绍学科 领域知识的同时, 鼓励学生对学科发展的最新动向和学科 内的疑难问题提出自己的看法, 鼓励学生保持科学的怀疑 态度, 敢于怀疑现有理论, 挑战权威, 提出自己的看法和 观点, 并与教师、同学一起讨论。在对问题争论的过程中, 学生通过提出自己的看法, 与老师和同学进行交流, 从而 培养了学生独立思考的习惯, 建立以研究生为主体的研讨 式教学模式。

结合现代教育技术和互联网为学生自主自学提供在线 学习平台。农业机械化工程所涉及的学科领域众多, 学生 的相关知识掌握得良莠不齐, 学生跨专业获取相关知识的 任务繁重。比如利用校园网络客户端, 建设学校特色的网 络教育教学平台, 将高校精品课程的教学视频、教学课件 
和相关学习资料发布到网站上, 可以为学生的跨专业自学 提供良好环境。在国内的部分高校, 这样的尝试正在进行, 并得到了师生的充分肯定。师生们普遍认为网络教学手段 的应用丰富了学生的知识面、提高了学生自主学习的能力。 总之, 这种教学方式能调动学生学习的自主性、积极性, 丰富学生的学习面, 使学生的个性得到充分发挥, 激发学 生的学习兴趣, 促进了学生科研创新能力的培养。

(4)加强实践能力, 营造创新环境。加大实验课程比例, 实验教学环节在农业机械化工程课程体系中有着重要的地 位。通过动手实验可以帮助学生更好地理解掌握专业知识, 学会通过所学理论知识解决遇到的工程技术问题、学习科 学的研究方法, 增强学生的动手意识, 培养自主创新能力。 由于目前, 实验室建设的投入相对较少, 实验设备陈旧, 实验器材不够完备。因此充分利用和开发现有的实验室资 源, 提高学生的动手能力在创新型人才培养中尤为重要。 目前在研究生课程设置中, 又进一步加大了实验课程的比 例。此外, 研究生根据课题需要组织科研团队也逐步在发 展。应该提倡这种机制并对其进行有效引导。例如聘请高 年级的研究生和实验室负责人作为团队负责人或指导人, 对研究生开放实验室, 培养学生动手能力, 积累科研项目 经验, 为培养学生的创新能力营造良好的动手实践机会。 在研究生理论学习阶段, 对各门课程的培养大纲进行了重 新修订, 除了专业基础课外, 对专业必修课、专业选修课 和专业方向课都加大实践环节。

走产学研相结合道路 [10], 在《研究生教育和专业教育 改革》一书中美国著名研究生教育学者梅黑幽曾阐述过, 研究生教育阶段不应是机械的教学训练, 而是引导学生开 发智力潜能, 培养学生进行科学探索和创造研究, 提高学 生的科学探索能力。基于我国国情, 目前大多数农业工程 院校与企业的联系、合作不够紧密。因此, 学生能够参与 工程实践锻炼与试验研发的机会较少, 其工程实践经验和 试验研发能力不足。为此要加强科研合作, 利用外联渠道, 走产学研相结合道路, 建立研究生实习训练基地和科研试 验创新基地。要通过各种渠道, 强化校企横向联合, 力争 外部支持的多元化、多样化, 建立长期互赢合作关系, 建 立并逐步建全研究生及导师科研创业基地, 实现科研稳定 投入、提高科研开发实力、加快科研成果转化。

\section{4. 实践结果}

(1)农业工程学科研究生课程配置上增加了创新方法课 程—-TRIZ 理论课程, 成立了“TRIZ 理论”兴趣小组, 普及、 推广和研究 TRIZ 理论, 使研究生的发明创新是基于科学的 创新方法进行的, 打破了研究生的思维惯性, 开拓了学生 的视野, 加强了研究生的创新效率和创新能力。培养研究
生掌握 TRIZ 理论应用技巧, 分析问题方法, 尤其在课题研 究中遇到的工程实际问题时能否可以通过 TRIZ 创新理论 来解决, 培养研究生科研创新能力; 组织研究生参加创新 设计大赛, 将 TRIZ 理论应用到发明创新中, 设计出多种结 构新渘的作品, 多次获得省级以上奖励, 申请多项发明专 利。

(2)制定了“农业工程学科全日制学术型研究生创新能 力基本要求及考核工作规定” 制度, 强化了研究生主动参与 各种创新实践活动, 加大实验课程比例, 全方位开放实验 室, 锻炼研究生动手实践能力, 提高了研究生的自主创新 能力。

(3)积极推进教学改革, 提倡讨论式、互动式、案例式 教学, 培养了研究生自主获取知识、发现问题、形成批判 性思维进而发展知识的能力, 实现了学生的个性培养。

(4)本校农业工程学科积极与周边的省黑龙江省农垦科 学院、佳木斯常发佳联农业装备有限公司等合作, 建立研 究生培养基地, 使研究生培养不在单一的校园环境中培养, 多接触实际课题, 大大提高了研究生的动手能力和创新能 力。

\section{5. 结论}

研究生科研能力的锻炼和学术水平的提升, 直接关系 到一个国家在以创新思维和创新能力为中心的科技实力的 发展。在更加注重创造市场经济价值的今天, 社会需求的 是具有认知面广、操作能力强、能够活学活用的创新型实 用人才。教育改革与时俱进, 研究生的教研模式、培养方 式也必须随之调整, 才能够适应时代进步的要求。本项目 在农业工程学科中进行研究生教学改革与创新能力培养, 使本学科研究生的科研创新能力和综合素质得到显著提 升, 体现以下四点:

(1)将创新方法 TRIZ 理论引入研究生培养机制, 加强 了研究生的创新效率和创新能力。

(2)在农业工程学科研究生录取后, 进行一次能力考试, 根据测试结果进行培养方式分类, 最大限度做到了因材施 教。

(3) 在理论教学阶段采用“启发式”和“讨论式”教学方 法, 实现了学生的个性培养。

(4) 在科研课题研究阶段, 加大实验课程比例, 并为课 程结业的成绩评定依据之一, 全方位开放实验室, 提升了 研究生科研能力。

\section{参考文献(References)}

[1] Li Qicai, Wu Xudong, Zhang Chuanjian, Li Zhongxin. The 
Study on the New-type Innovative System Construction of Agricultural Mechanization in Shandong Province. Journal of Agricultural Mechanization Research, no. 6, pp.7-10, 2006

[2] Li Yao, Shan Anshan, $\mathrm{Hu}$ Shuqing, etc. Disciplinary Construction and Cultivation of Innovative Graduates, Journal of Northeast Agricultural University(Social Science Edition), no.5,2009.

[3] Zhang Jun, Li Xiaoyu, Wang Wei, Liu Jie. Discussion of cultivating Agricultural Mechanization Engineering Graduates' innovation capability. Higher Agricultural Education, no.1, pp. 75-77,2008.

[4] Wang Yongsheng. Comparisons of the Development of Graduate Education Between in China and U.S.A. Comparative Education Review, no.3, 2000.

[5] Li Xiaoxing, Wang Wei. The Implications of Foreign Graduate Training Mode to china's cultivation of innovative Talents. Proceedings of China Agricultural Machinery Institute Conference 2008 Annual, pp. 489-492.

[6] Ren Yongtai, Lu Tieguang, Cao Haifeng. The Research and
Optimization Strategy of the Graduates' Curriculum System under the Mode of Training Innovative Talents. Journal of Northeast Agricultural University: Social Science Edition, no.6, pp. 60-62, 2012.

[7] Tu Dan, Wang Yun. Reflection on the Graduate Students' Major Course. Journal of Higher Education Research, no.6, pp. 71-73, 2007.

[8] Zhou Naijun, Pei Hailing. Using the Postgraduate Education Patterns in Developed Countries for Reference to Analyze the Chinese Postgraduate Education. Journal of Higher Education Research, no.6, 2006.

[9] Zheng Jinhai, Su Qing. Practice and Thinking of the Joint postgraduate training base construction. Jiangsu Higher Education. no.6, pp.90-91, 2011.

[10] Liu Min, Zheng Jiangying, Chen Fangqing. The explorations for enhancing the Participation of SMEs Cooperation with local universities to graduates' Joint training. China Education Innovation Herald, no.34, pp. 10-11, 2009. 